\title{
ARE THE BENEFITS OF INTEGRATED CATCHMENT MODELLING BEING REALIZED IN THE UNITED KINGDOM?
}

\author{
WILLIAM RUST \& PHOEBE VENN \\ Infrastructure, Atkins, United Kingdom
}

\begin{abstract}
Historically, hydrological systems have been modelled separately to investigate flood risk. This is due to computational limits and the devolved responsibilities set out in the existing legislation for risk management authorities. This method may result in the true impact of flooding being misrepresented as the interaction between hydrological systems and drainage infrastructure unaccounted for. In contrast, integrated catchment modelling (ICM) is a methodology in which various hydrological systems are explicitly represented in a single flood model. This enables more realistic assessments of flooding sources and mechanisms, and allows for improved communication of risk. This article provides an overview of the use of ICM in the UK; discusses the benefits of and barriers to the use of ICM; and provides case studies that demonstrate the benefits of ICM for multiple end users. Cost-benefit analyses are traditionally carried out using results from separate models, and alleviation schemes are developed and funded based on the outcome. The economic benefits may be underestimated and the scheme under-designed due to inaccuracies inherent in separate modelling approaches. The use of ICM allows for the development of flood alleviation schemes (FASs) that provide multiple benefits by protecting people, properties and infrastructure at risk from combined sources of flooding. As set out in the Flood and Water Management Act 2010, Lead Local Flood Authorities (LLFA) are responsible for strategic flood risk management and as a result are moving towards the use of ICM to open more funding streams for FAS development. ICM provides a tool that demonstrates to multiple stakeholders how they can benefit from a single alleviation scheme. This increases the chances of a scheme reaching construction due to greater funding potential. While there are still barriers to the use of ICM, the benefits are beginning to be realized by LLFAs and other regulatory bodies. Keywords: flood economics, flood risk management, integrated catchment modelling, hydraulic modelling, partnership funding
\end{abstract}

\section{INTRODUCTION}

A key issue that faces flood risk managers in the UK is the procurement of funding for the construction of flood alleviation schemes (FASs). Funding is dependent on two factors: a favourable cost-benefit ratio (BCR) for the scheme construction, and sufficient partners or stakeholders willing to contribute capital and maintenance costs towards a scheme. Given the complex interactions between flooding and the ever developing urban environment, establishing a robust $\mathrm{BCR}$ can be problematic without a comprehensive view of integrated risk mechanisms. Additionally, an incomplete view of all flood risk sources can limit the number of partners who may be shown to be benefiting from, and therefore willing to contribute towards, a scheme. A sufficient view of integrated flooding mechanisms is therefore crucial for successful scheme implementation in many urban areas.

Partnership funding (PF), where money for a scheme is accrued from multiple stakeholders, provides a mechanism for stakeholders to financially contribute towards a FAS. This is usually used in conjunction with government funding from the Department for Environment, Food and Rural Affairs. The Environment Agency (EA) has a national target to obtain 15\% of funding for FASs, from non-governmental money throughout the period 2015-2021 [1].

As set out in the Flood and Water Management Act 2010 [2], the responsibility for managing the different sources of flood risk is divided between separate regulatory bodies. 
This devolution of responsibilities means that hydrological systems are often assessed in isolation to predict flood risk. Given the integrated nature of flooding between natural drainage and man-made infrastructure in the built environment, a siloed approach to assessing flood risk can result in an inaccurate understanding of flood risk in many urban areas. Historically, models have been developed to assess single-source risk for use by individual regulatory bodies (e.g. surface water drainage or river networks). In addition to an incomplete view of flood risk sources and mechanisms, this siloed approach means funding efficiencies are often lost where combined-system flooding prevails. With the growing demand for new development in the UK, flood mechanisms are becoming increasingly integrated, and the need to understand combined flooding is becoming more important, which cannot be easily achieved with the current approach.

In addition to legislative restrictions, hydraulic models used to understand flood risk and develop alleviation schemes have historically been simplified due to computational limitations. However, the increase in computational ability in the past two decades now allows hydraulic models to estimate larger and more complex, integrated flooding issues. Integrated catchment modelling (ICM) is a concept in which multiple connected hydrological systems across entire catchments are explicitly represented in a single flood model. This enables more realistic assessments of flooding sources and mechanisms, therefore, allowing an improved understanding and communication of risk. ICM provides a tool which demonstrates to multiple stakeholders how they can benefit from a single alleviation scheme. Using the results from integrated models to develop alleviation schemes can increase the BCR as it allows for a single scheme to be developed to protect people and property from combined sources of flooding. Consequently, the increased number of stakeholders benefitting from a scheme opens more funding streams for PF. Despite these developments in modelling ability, many FASs undertaken in the UK today still use siloed modelling approaches for combined urban flooding issues. This means fewer schemes are able to progress to design and construction as the number of stakeholders involved is limited.

This article will review three recent case studies where ICM has been used to inform a more complete view of combined flood risk and open more funding streams from stakeholders. These case studies will then be discussed within the wider context of adoption of ICM approaches, and the current barriers to the use of ICM in the UK.

\section{CASE STUDIES}

\subsection{M1 junction 4-5 flood study}

The M1 carriageway between junctions 4 and 5 is prone to flooding with a history of standing water on the carriageway, which has caused significant disruption to vehicles. The M25 Design, Build, Finance and Operate study identified this section of the M1 as the number one flood hotspot within the study area. Drainage improvements, such as recessed gullies and new drainage conduits, have been made in an attempt to reduce the impact of flooding. However, these improvements, coupled with an enhanced maintenance regime, have provided no reductions in flooding.

Atkins was commissioned by Highways England (HE) and Connect Plus Services to assess the flood risk areas, sources and mechanisms on the M1 between junctions 4 and 5 and to develop conceptual alleviation scheme designs. It was decided to use ICM to determine the mechanisms of flooding on the carriageway. This was because the flooding was 
not represented in existing separate hydrological system models, such as fluvial or highways drainage, and an integrated catchment model is able to represent the combined systems, allowing for a more efficient alleviation scheme to be designed.

The M1 is located in a cutting through the fluvial catchment of the Hilfield Brook. The study area primarily focused on the carriageway between junctions 4 and 5 on the M1. The Hilfield Brook and Tykes Water catchments were also included to take into account overland flow and the fluvial component of the Hilfield Brook catchment. The catchment is largely agricultural fields with some residential areas.

Traditionally, highways drainage systems are designed using hydraulic models that apply rainfall to the road and allow for a small percentage increase in the rainfall to runoff from the wider catchment. In the case of the M1, it was clear that, due to the location in a cutting, the surface water runoff would be a key component of the flood risk. The Atkins team determined that an integrated catchment model with the rainfall, fluvial network and drainage infrastructure represented would better assess the flood risk, sources and mechanisms. The model boundaries were set using the Hilfield Brook and Tykes Water catchment boundaries as illustrated in Fig. 1, and LiDAR was used for the ground model to simulate runoff over

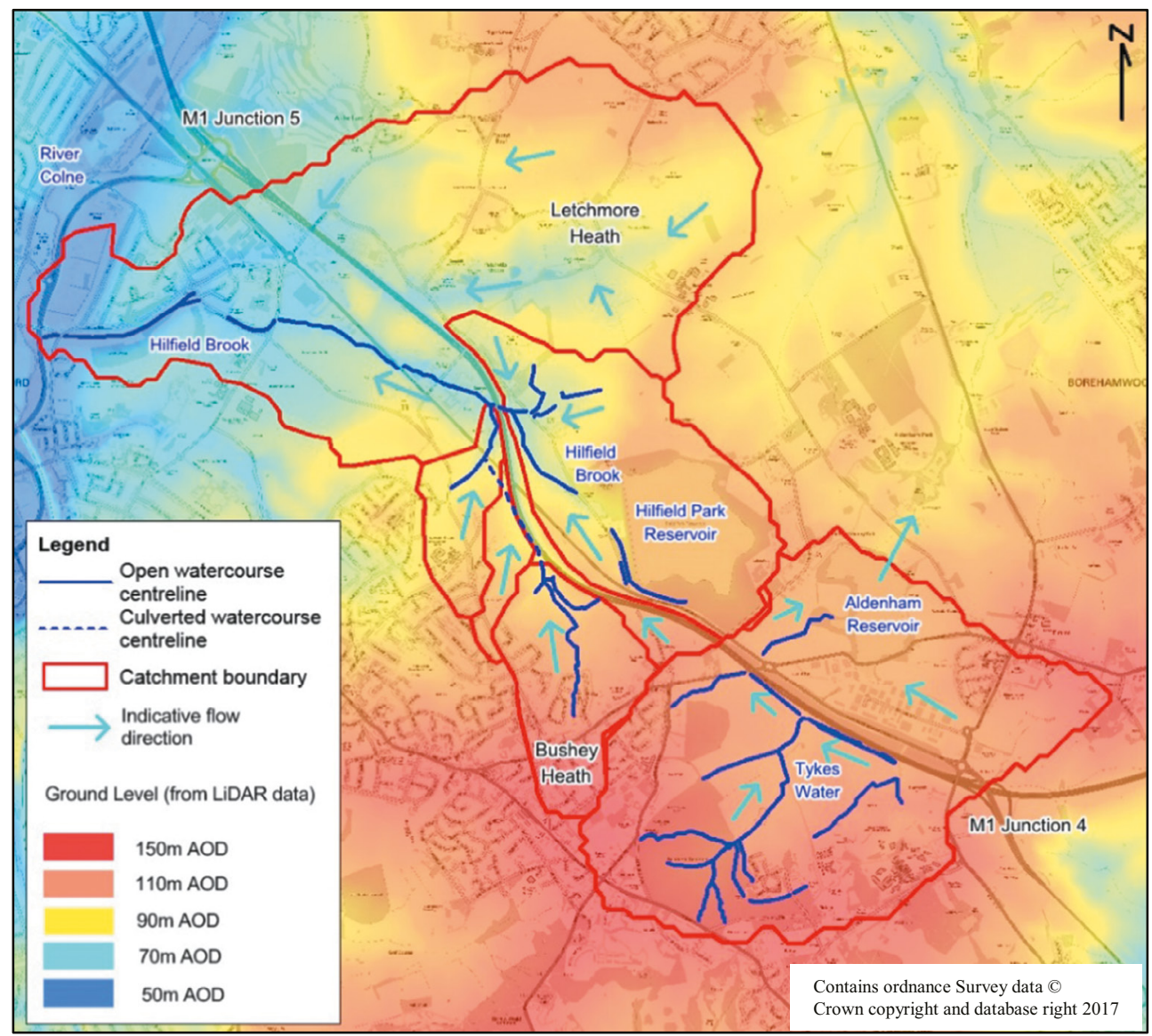

Figure 1: M1 study area catchment showing ground levels, water courses and flow paths. 
the ground surface. The highways drainage infrastructure was imported from HE data, and the Bushey Heath urban catchment was represented using Thames Water drainage data. The EA's Hilfield Brook fluvial model was imported into the model including the structures, such as bridges and culverts.

During heavy rainfall events, the capacity of the highways drainage infrastructure on the M1 is exceeded. This, coupled with the surface water flow paths from the surrounding catchment and the carriageway's location in a cutting, means that flow runs down the motorway, causing significant disruption to drivers. There is a large flow path which originates from the Bushey Heath urban area, which is conveyed to the Bushey Heath drain by the surface water drainage infrastructure (Fig. 2). This flow is too great for the Bushey Heath culvert to convey safely downstream into the Hilfield Brook; therefore, it runs down the hill onto the M1. The baseline flood risk identified using ICM was verified using recorded flood information, including CCTV footage and photographs.

This updated model and recorded flood information differs from the EA's existing fluvial model, which solely models the fluvial inflow in the Bushey Heath drain and Hilfield Brook (Fig. 3). The existing EA model does not consider surface water input from the surrounding catchments. This EA fluvial model shows that the Bushey Heath culvert is able to convey the flow during a $0.1 \%$ AEP event. In contrast, the new ICM approach suggests that the capacity of the culvert is exceeded during lower intensity storm events. The improved understanding of the baseline flood risk locations, sources and mechanisms provided by the combined model enabled identification of conceptual options to better manage combined flood risk on the M1.

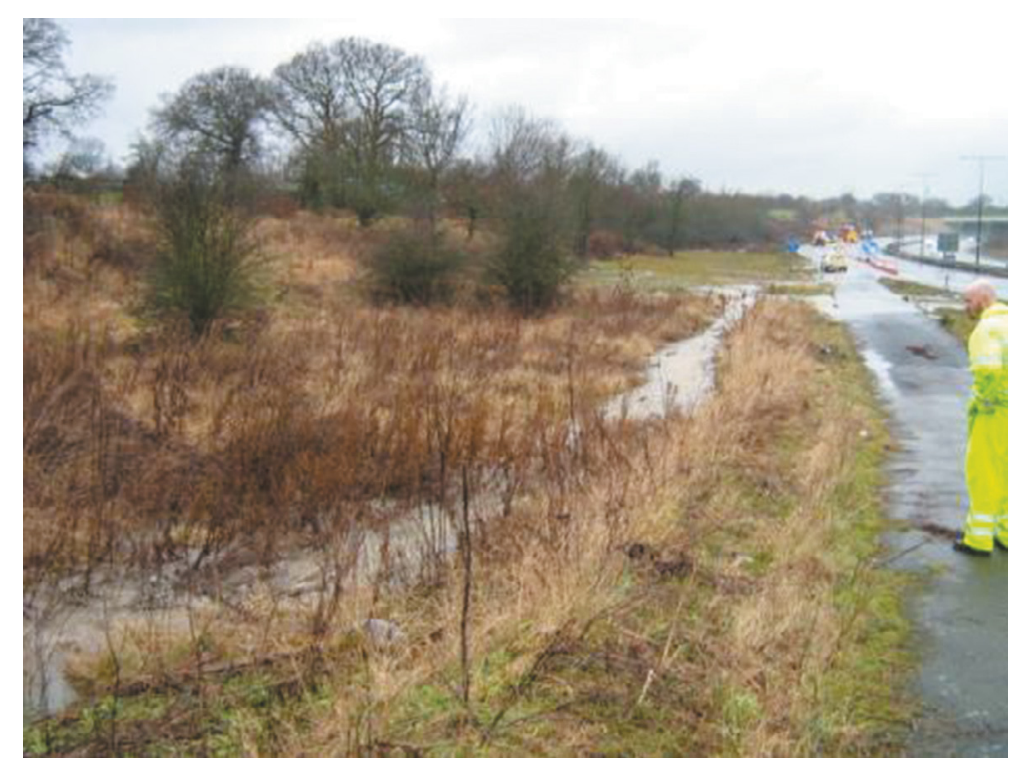

Figure 2: Photo of flood water running down from the Bushey Heath urban catchment onto the carriageway on 11-15th January 2008, facing north. 

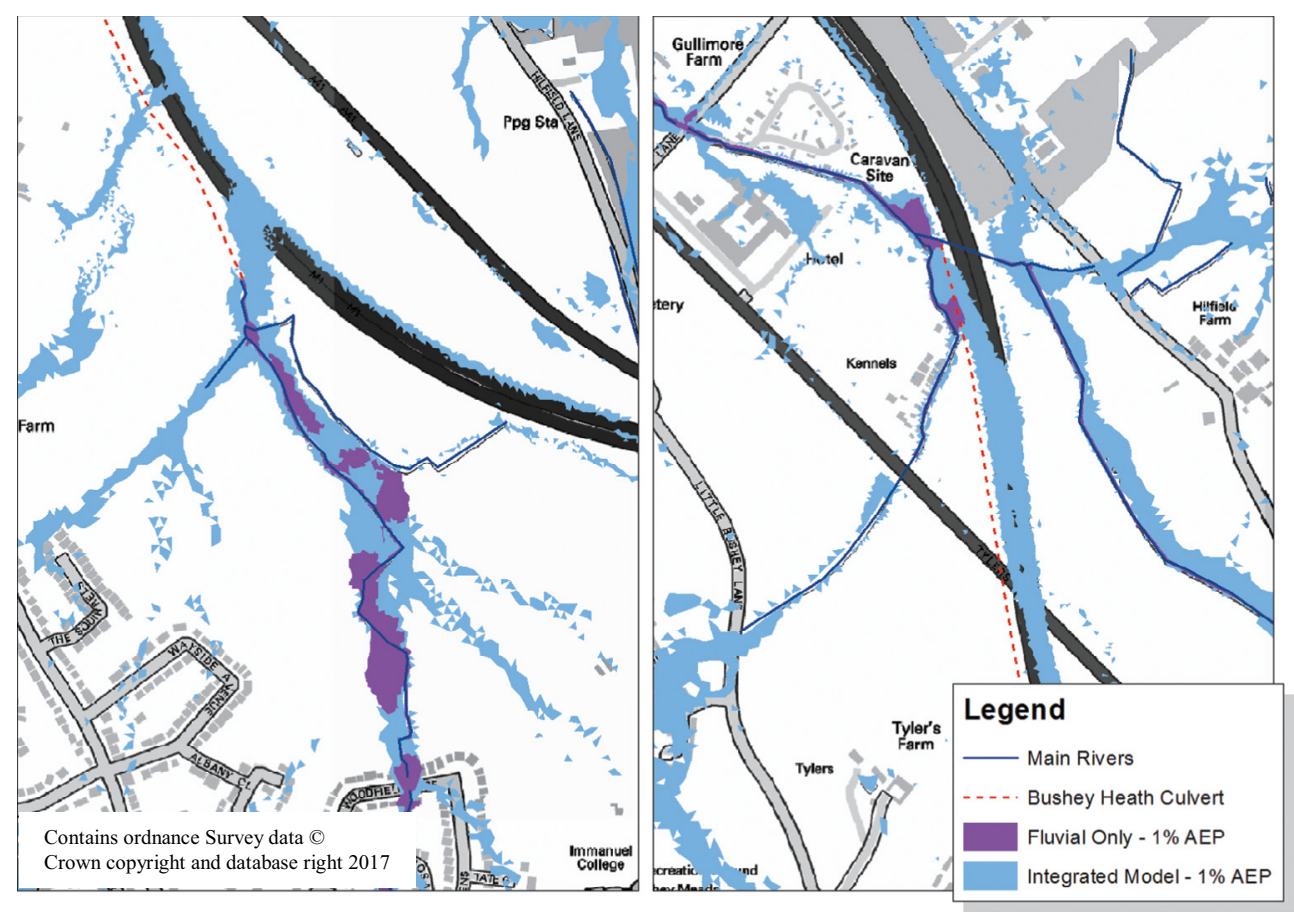

Figure 3: Comparison of modelled flood outlines between EA fluvial flood maps and the M1 combined model (annual exceedance probability (AEP) is the chance of a given flood event being exceeded in any given year).

\subsection{Oxford flood alleviation scheme}

According to the Flood Risk in Oxford policy paper from the EA [3], there are 4,500 properties in the city at a $1 \%$ (or higher) annual risk of flooding. Following the Oxford Flood Risk Management Strategy [4], the EA commissioned the construction of a river-only hydraulic model to quantify and develop plans to alleviate fluvial flood risk. This hydraulic model was built in ISISTuFlow; software was designed to simulate in-channel and surface routing hydraulics for the purpose of fluvial flood modelling. The design of the Oxford Flood Alleviation Scheme (OFAS) was undertaken using the results from the river-only model. The design comprises a two-stage alleviation channel and associated retention bunds costed at approximately $£ 100 \mathrm{~m}$ [5]. The OFAS was designed to raise the current standard of protection to $1 \%$ annual risk.

Thames Water was interested to understand the effect that fluvial flooding had on their drainage system, and to what extent the proposed OFAS would benefit their network. They commissioned Atkins to use ICM to investigate the combined issue of fluvial, surface water and sewer flooding within the Oxford sewer catchment.

The OFAS integrated model revealed that a portion of the Thames Water network was affected by the inundation of flood water from fluvial sources. This was resulting in hydraulic overload of the sewer network. The integrated view of flood mechanisms, provided by the ICM approach, allowed Thames Water to update the source of flooding for certain assets in their risk database from 'sewer' to 'fluvial'. 
The combined model was also used to assess the impact of the proposed OFAS on Thames Water's sewer network. While the fluvial-only ISIS-TuFlow model was suitable for fluvial FAS development, it was not able to describe any benefit to the urban drainage network. This was because the ISIS-TuFlow model only replicated flooding from the river channel with no interaction with the urban drainage network. As such, this approach precluded other potentially interested stakeholders from understanding the benefits of the scheme, thereby limiting PF opportunities (Fig. 4).

A comparison between existing flooding and OFAS flooding within the model showed that the OFAS reduces flooding and provides a considerable benefit to the Thames Water network, as a result of reducing fluvial water ingress to the sewer network. This benefit allowed Thames Water to understand what contribution they may be able to make towards part-funding the OFAS. This was only possible by using a combined view of flooding between fluvial, surface water, and sewer networks.

With the development of the OFAS combined model, all further optioneering can be carried out using the representation of combined risk provided by the model.

\subsection{Rive catchment study}

Atkins was commissioned by Surrey County Council to consider the flood risk at five locations within the town of Woking in Surrey, UK, following the delivery of the Rive Ditch Constraints Assessment project [5]. This assessment investigated the viability of multiple flood

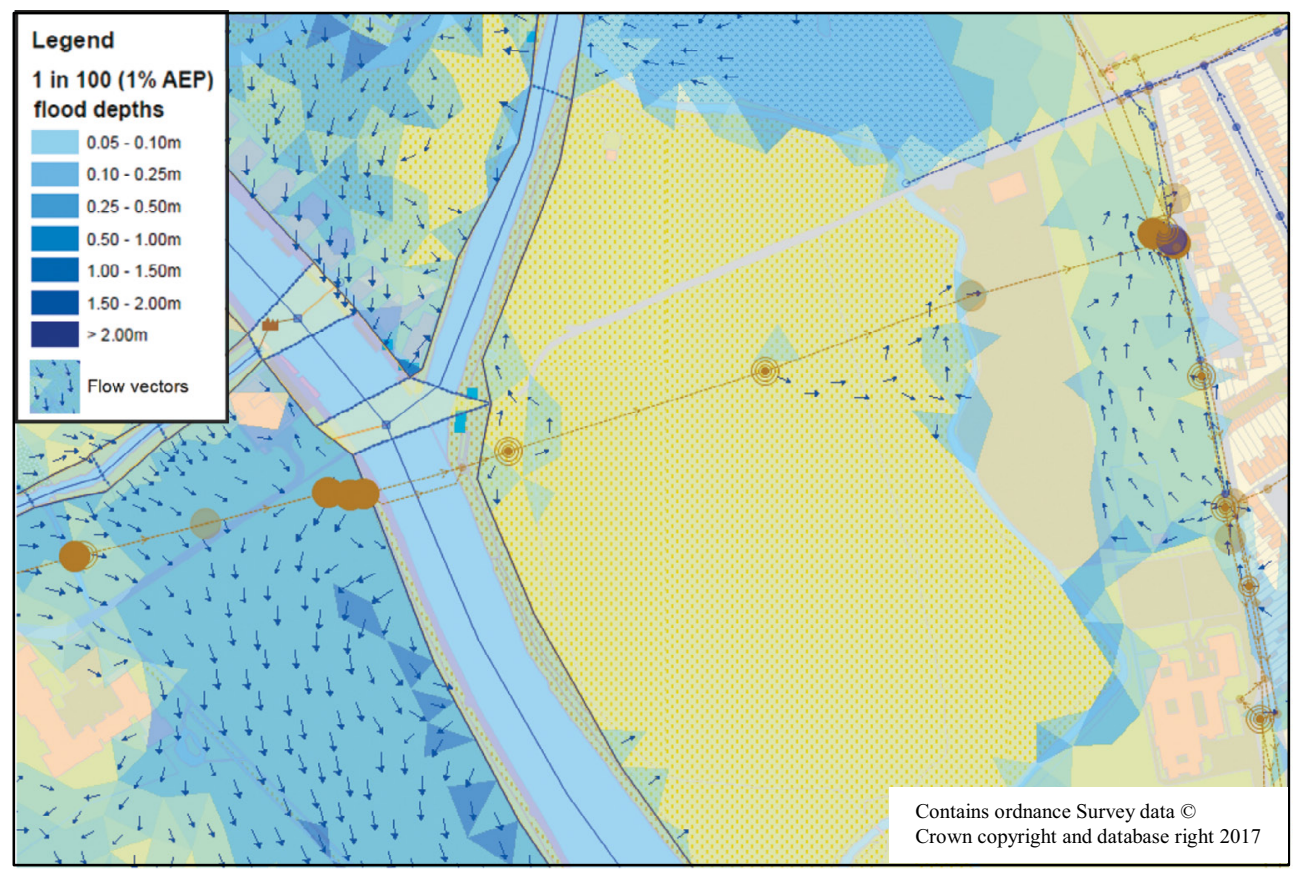

Figure 4: Model output showing integrated flooding between sewers and rivers in the Oxford integrated model. 
attenuation schemes in the Rive catchment. Therefore, for the next stage, Atkins proposed to undertake the assessments collectively by developing an integrated catchment model. The use of ICM was chosen because it is more cost effective than using separate models for each location; it provides a more effective tool for making strategic flood management decisions; and it would be easier to develop for future studies.

To facilitate collaborative working on the Rive Catchment Assessment, a Project Board consisting of the following organizations was established:

- Surrey County Council

- Woking Borough Council

- Runnymede Borough Council

- Environment Agency

- Thames Water

- Network Rail.

The combined flood model represents the watercourses, canals, ground surfaces, buildings and foul and storm water sewers within the Rive Catchment. The model includes over $36 \mathrm{~km}$ of watercourse, $477 \mathrm{~km}$ of pipes (including culverts) and 8,663 manholes. This combined model was calibrated to recorded flood events and gauged flows to ensure a more robust representation of the combined flood mechanisms. A range of flood risk mitigation options were identified through stakeholder consultation and simulated in the model.

The use of ICM allowed for a better representation of combined flood risk, compared with the original fluvial-only flood models. This meant that various alleviation schemes could be taken forward for further option assessment, as the integrated model showed that there were more benefits than the fluvial-only models. Additionally, the presence of the Project Board with multiple stakeholders, as facilitated by an ICM approach, has also allowed schemes to be developed with full approval from the stakeholders.

By using ICM from the start of this project, a collaborative approach has been used from risk assessment through to option development. This enables all future assessments and developments to address multiple sources of flooding and all stakeholders' interests.

\section{DISCUSSION AND CONCLUSION}

The aim of this article is to outline the benefits of ICM and to determine whether these benefits are being realized in the UK.

The benefits of using ICM for the development of FASs have been explored using three case studies in this article. These examples show that an ICM approach can provide a better representation of combined flood risk in urban areas over traditional 'separate' models. This is due to the representation of the dynamic interaction between different hydraulic and hydrological systems allowed by using ICM. This has been demonstrated well by the M1 Junction 4-5 Flood Study, for which an ICM approach enabled the significant improvement of flood estimation over previous approaches, enabling the development of more effective flood alleviation options.

These examples also provide evidence that an ICM methodology can generate increased interest and awareness of a flooding issue from a wider range of stakeholders, thereby increasing PF opportunities. The OFAS and the Rive Catchment Study demonstrate how using ICM can provide a robust and fuller project stakeholder group which increases the likelihood of a scheme reaching the required PF target and, therefore, progressing to design and 
construction. The examples show that ICM simplifies the process of stakeholder engagement, given the wider view of flooding mechanisms, sources and receptors.

The ICM methodologies discussed in this article allowed the clients to better understand the risk to their (and others') assets meaning that flood alleviation options can be developed to protect against a broader range of combined risk. As such, ICM provides a methodology to build more robust benefit-cost ratios due to the efficiencies that can be made in the alleviation of multiple sources of risk. The increased BCR enables the alleviation scheme to be taken through to design and construction. Due to the combined ICM methodology, there is inherently a larger number of stakeholders engaged in a flooding issue, compared with separate modelling approaches. This allows increased PF opportunities, ensuring that the schemes are fully funded and taken through to construction. These benefits are significantly harder to achieve using separate or siloed modelling approaches.

While this article has shown evidence that an approach using ICM yields improved outcomes over separate modelling, there are still inhibitors to the wider adoption of ICM in the UK. An initial willingness is required from the client or regulatory body to invest in an ICM approach. Given the devolution of responsibilities for different flood source risks across different management bodies in the UK, it can be difficult to show the benefit of ICM beyond the remit of their responsibilities.

As set out in the Flood and Water Management Act 2010, Lead Local Flood Authorities are responsible for strategic flood risk management. As a result they are moving towards the use of ICM to open multiple funding streams for FAS development. In order to encourage more regulatory bodies to adopt the use of ICM, there needs to be a change in the industry mind-set regarding strategic flood risk management. If the EA is to reach the target of $15 \%$ PF contribution to its FASs by 2021, there needs to be increased cooperation between risk management authorities and stakeholders to provide a driver for stakeholder investment. This article has shown that ICM can provide a robust methodology to achieve this requirement. At present, the devolved responsibilities set out in the Flood and Water Management Act (2010) [2] do not encourage collaboration or the assessment of the risk as an integrated issue. The EA's 6-year investment programme states a target of reducing the risk of flooding to 300,000 properties by 2021 [1]. This number could be more easily achieved with the use of ICM as more properties could be protected from combined flooding with a single scheme, compared with protecting against single sources of flooding.

\section{REFERENCES}

[1] Defra. Reducing the risks of flooding and coastal erosion - an investment plan; 2014.

[2] UK Government. Flood and Water Management Act; 2010.

[3] Environment Agency. Flood Risk in Oxford policy paper, available at https://www.gov. uk/government/publications/flood-risk-in-oxford/flood-risk-in-oxford, 2016 (accessed 1 March 2017).

[4] Oxfordshire County Council. Local Flood Risk Management Strategy, available at https:// www.oxfordshire.gov.uk/cms/content/oxfordshire-local-flood-risk-managementstrategy, 2010 (accessed 1 March 2017).

[5] Oxfordshire County Council. Environment and Planning, available at https://www. oxfordshire.gov.uk/cms/content/oxford-and-abingdon-flood-alleviation-scheme, 2017 (accessed 1 March 2017).

[6] Atkins. Rive Ditch Constraints Assessment; 2013. 